\title{
Natural building systems: experiments in urban ecology
}

\author{
K. Connors \\ State University of New York at Buffalo, USA
}

\begin{abstract}
Natural building and alternative material use have evolved gradually in the United States over the past 40 years, mostly in rural situations, often outside what Ann Cline calls the "Circle of Architecture". With few exceptions, such as Portland, Oregon and Madison, Wisconsin, urban natural building has not taken a strong hold. The Rural Studio of the late Samuel Mockbee represents the quintessential design/build pedagogy for the socially conscious architecture curriculum in a rural setting. This paper describes the convergence of natural building, design/build pedagogy, and the support of an emerging culture of urban ecology in Buffalo, New York, by chronicling student work at the University at Buffalo. The design/build seminar course, Natural Building Systems, explores a range of alternative building materials and, through service to existing non-profit groups practicing urban agriculture, employs these materials in a participatory design/build process.
\end{abstract}

Keywords: natural building, design/build, urban ecology, alternative materials.

\section{Introduction}

Kennedy [1] describes the growth of the natural building movement through the vehicle of colloquia, beginning in 1994 in Oregon: "The many disparate efforts to relearn ways of building with local materials and adapt them to modern needs have been brought together into a single conceptual basket with an easily understood name: "natural building." The purpose of Natural Building Systems is twofold: to introduce natural building to students of architecture and to implement design/build projects that reinforce existing urban neighborhood revitalization initiatives. 
The collaborative teaching team consists of the author, a local natural builder (D. Lanfear) and an Intern Architect (S. Heiser). The seminar began with only a rough outline of planned research in order to allow for improvised material research. Once clients were selected through an RFP (Request for Proposals) process, programming and design commenced in parallel with material research.

From a pedagogical perspective, Natural Building Systems was conceived as both a materials and methods laboratory and a studio. It was intended to provide an opportunity for direct experience and experimentation as the basis for architectural inquiry, and aimed to utilize natural and recycled materials while facilitating community volunteers in the participatory building process.

\section{Research in natural and found materials}

The seminar began with an introduction to natural building concepts through images of built works and construction processes, and discussion of the activities of a design/build project. One specific focus of the seminar was the discovery through action of the properties of natural materials, especially earth as a building material.

\subsection{Cob making}

There can be no better introduction to earthen materials than making cob. Given that the seminar began in January in Buffalo, it was necessary to acquire bagged clay and sand to create the cob mixture. A few straw bales were obtained from a local barn and the studio was transformed into a workshop. The design mix consisted of roughly a ratio of 1:3:1 (clay: sand: straw) by volume.

Domestic students generally were treated to a new experience, whereas some foreign students were familiar with the ambulatory mixing process, fig. 1 . The crude mixture was made into small bricks with wood reference strips to register shrinkage. They were left to dry.

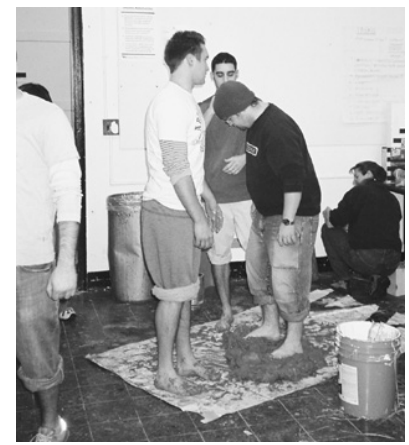

Figure 1: Cob mixing.

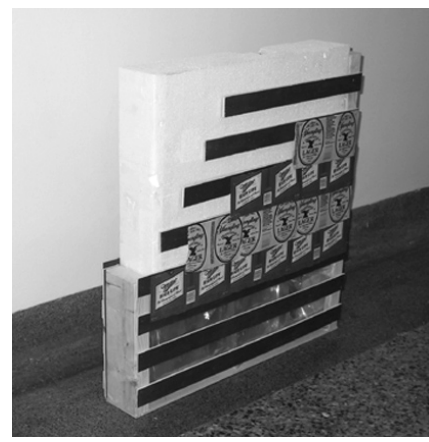

Figure 2: Found material wall assembly. 


\subsection{Scavenger hunt}

Besides natural materials, natural building strives to use discarded and recycled materials. Examples include Reynolds' rubber tire Earthships, or the silo sections of Jersey Devil creations. Retrieving usable materials, otherwise destined for the landfill, demands a watchful eye. The skill must be cultivated.

The first assignment of the seminar was a group project to find and assemble into a building system materials from a waste or scrap source. Students proposed all manner of compositions for wall components and assemblies, fig. 2, often using shipping pallets as a frame, with various infill materials. Aluminium cans were used to create cladding shingles, sheet metal scraps for roofing.

\section{3 "A Hut of One's Own"}

A single text was assigned for the seminar, a delightful book of this title by Ann Cline [2]. The hut represents the primitive and the personal, the refuge and the ritualized experience. It situates architectural experience in the process of making, and opens the world of materiality to modest, even banal, constructs. It argues, in part, for a world that is directly lived: "How, indeed, do we regain a world that is directly lived, as it was for the Chinese recluses and the desert fathers, or as it is now for some of today's homeless." [2]. It was precisely the open-endedness of the hut as a model for architectural inquiry that suggested it as the inspiration for the next work.

\subsubsection{The de-constructable hut}

The second assignment called for the construction of a de-constructable hut; that is, one possessing the ability to be readily taken apart and rebuilt, fig. 3 . It was to be built first in our studio space and then relocated to the project sites. Two groups were self-formed to work on two huts (for two clients, sites and projects).

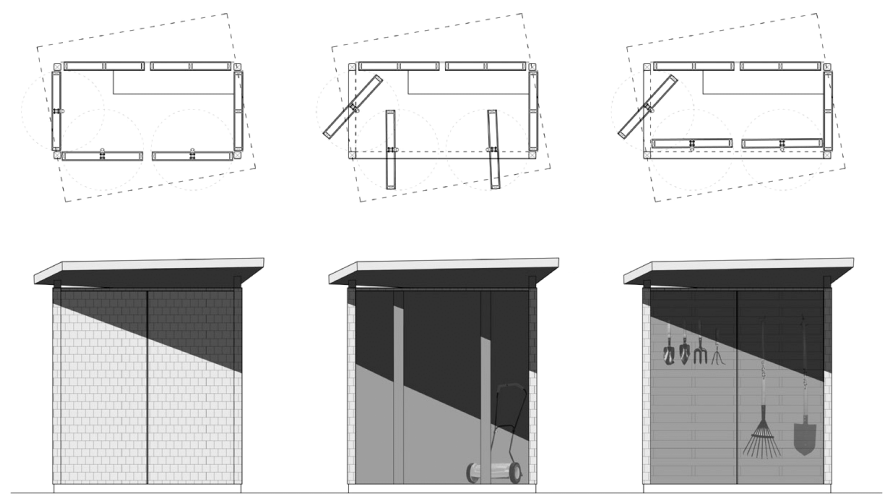

Figure 3: A transforming tool shed. 
The groups were given the freedom to interpret the program for the hut as they saw fit. The only prerequisite was that the two huts fit in the studio space. The unwritten assumption was that to be "huts" they should accommodate the practice of "hanging out." However, as the process of identifying the potential clients evolved, the program for the huts transformed into utilitarian structures tool sheds.

\subsection{Papercrete}

In the spirit of open space, the faculty responded to a student request to experiment with papercrete (a mixture of cellulose and a binder). This afforded the opportunity to make an investigation of the properties of various binder materials. Pulverized slag (a steel manufacturing by-product) and fly ash (a coal combustion product) were donated by a ready-mix concrete supplier. All the other materials were readily available.

Students self-assembled in six groups to mix various proportions of the cellulose pulp with a selected binder. They were also encouraged to experiment with multiple binder materials. A five-gallon container was premixed with a blended mash of newspapers and water. Dry cellulose insulation was also available to mix fresh pulp.

Samples were prepared in small plastic cylinders for compression testing, fig.4. Since some of the binders did not chemically depend upon the water content, they required a considerable length of time to set (dry). The combinations of binder proportions varied in terms of volume or weight. The compression testing was planned for later in the term.

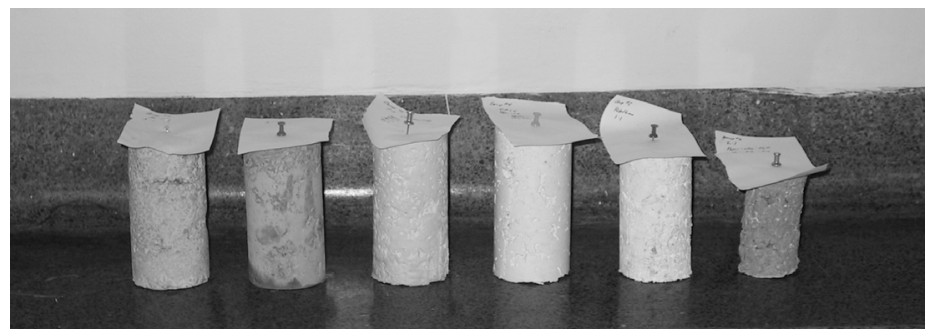

Figure 4: $\quad$ Papercrete samples (1 to r: Portland cement, fly ash, slag, Plaster of Paris, lime, and clay).

\subsection{Load-bearing strawbale wall}

The planned research entailed the construction of an earth plastered strawbale wall and its gravity load testing. An eight-foot long by eight-foot high wall was constructed with a wooden base (toe-up) at the bottom and box-beam at the top. Two-string bales were stacked on edge - straws in the vertical direction. Fencing wire was used in a vertical loop at each end to help align and slightly pre-compress the bales between the toe-up and box-beam, fig. 5 . 


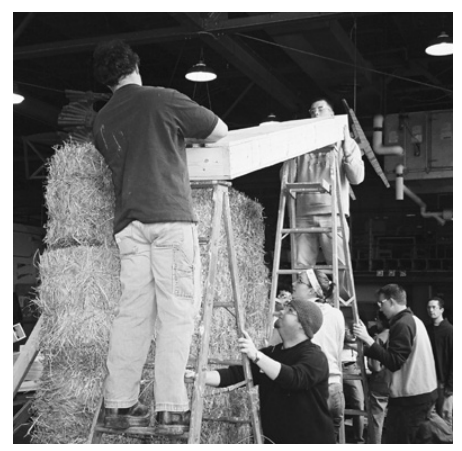

Figure 5: $\quad$ Strawbale mock-up wall.

The plaster mix was from local hand-excavated clay loam. It was mixed into a thick clay slip with a paddle-style mixing bit on an electric drill. Some of this was first thinned and sprayed onto the stacked strawbales using a pneumatic sprayer with an attached hopper. This created a natural bonding agent for the earthen plaster. Straw was chopped using a mulching attachment on an electric leaf blower. The plaster was mixed by volume in the proportion of 1:2:1 (slip: sand: chopped straw). After voids in the bare wall were packed with straw and cob, the first coat of plaster was applied by hand.

Due to the difficulty in obtaining clay directly from the ground, bagged dry clay was ordered for the balance of the plasters. Load testing of the wall was planned after the spring break.

\section{Design/build process}

One premise of a successful design/build project is that early comprehension of the whole is essential. Since the effort would be collaborative, this is necessarily a group process. Part of the first week was devoted to brainstorming a list of tasks or activities necessary to complete the design/build project. The students generated a list that was put into a rough Gantt chart. Among the activities identified was the task of managing the tasks of the whole group.

\subsection{Roles of students}

In the second week, students were asked to choose a task or tasks on which to take initiative. As the tasks were distributed over the course of the projects, some individuals were at first freed up to participate more in the testing program. As the semester progressed, roles further evolved as teams self assigned specific tasks in the development and presentation of their design concepts.

\subsection{Scheduling}

The original Gantt chart was followed as closely as possible. As tasks slipped in one area, other activities were moved forward to keep the process moving. As in 
any complex endeavor, multi-tasking was essential. The teams were simultaneously responsible for designing their de-constructable huts, researching natural building materials and techniques, constructing test specimens and the mock-up wall, meeting with clients, and doing site analysis. As the projects moved forward, the design and presentation activities took precedence since timely client approvals were essential to the critical path.

\subsection{Participation}

Ultimately the goal of the design/build process is to involve students with members of the non-profit organizations, neighbors and families, other members of the University community, and various levels of the city bureaucracy. This connection is an integral part of community building that has been tremendously successful in cities such as Portland. Practicing simple natural building techniques, experienced community members can move forward with additional phases of work, and become teachers of volunteers in the development of other urban natural building initiatives.

\section{Locating urban ecology clients}

In order to optimize the design/build schedule for the semester, the process of soliciting clients began prior to the start of classes. By canvassing faculty and community leaders involved with various non-profit organizations, a list of approximately 20 contacts was formed. A draft Request for Proposals (RFP) was prepared and reviewed with the students in the first week of classes. It was issued to prospective clients at the end of the first week.

\subsection{Request for proposals/evaluation}

The RFP was a Natural Building Systems Grant announcement. Specific requirements included legal ownership or control of land, funding for materials and fees, general liability insurance, and a community of volunteers to participate in the actual construction.

Two organizations responded with proposals for projects: The Massachusetts Avenue Project, and Street Synergy Community Association. Volunteer students reviewed the proposals. They identified issues of scope and size, compatibility with natural building techniques, and the need for further clarification. Meetings with the respondents were set up. Ultimately, we determined that given the number of students in the class (17) and the merits of each proposal, we would offer two Natural Building Systems grants.

\subsubsection{The Massachusetts Avenue Project}

The Massachusetts Avenue Project (MAP) was established in 1992 to "organize and implement projects to build and revitalize Buffalo's West Side.” [3]. Their core programs include Growing Green, a youth oriented urban agriculture project and Food Ventures, a micro-enterprise development program. MAP occupies several connected vacant parcels and one with a frame dwelling 
housing one of the project facilitators. MAP's proposal included the possibility of a new greenhouse, exterior bake oven, and a tool shed to support the urban agriculture program.

\subsubsection{Street Synergy Community Association}

Street Synergy Community Association (SS) was organized in 1999 to improve "the integrity and strength of Buffalo's University District neighbourhoods and to improve the community's quality of life." [4]. SS programs include Better on Bailey, a business development and façade improvement project for Bailey Avenue, and Clean and Secure, an initiative to maintain order and cleanliness in the low to moderate-income neighborhood as a means of fighting blight and crime. SS developed a garden project at the site of a former restaurant and apartment building that was destroyed by fire. This city owned property was the focus of their proposal, which included potential projects for a garden wall, entry gateway arch, greenhouse and tool shed.

\subsection{Programs/programming}

The two clients shared similarities in constituencies and programs. Indeed, the SS gardening program aspires to become more like that of MAP. Both need the support and leverage of positive changes, especially physical improvements, to advance the impacts of their programs. They have similar programmatic needs (gardening and agriculture) and concerns (e.g., safety and security). Coincidentally, they both involve adjacent houses that have been previously considered for demolition.

In particular, the SS site has an adjacent house that, if stabilized and renovated, could provide space for educational programs, gardening support, and a working greenhouse at a relatively modest cost. The boarded up south facade is ideally suited for greenhouse adaptive reuse. From a sustainability perspective, we advocated for reuse, or as a last resort, de-construction and salvage of the components of the vacant house.

\section{Planning and design}

\subsection{Contextual response}

For each client, students used aerial mapping, Sanborn maps and physical measurements to document the sites. The MAP site is a newly created common space within an established residential neighborhood. The SS site belongs to an old commercial strip flanked by residential neighborhoods in the vicinity of the University at Buffalo. The context of each was a distinct type.

The students met with client representatives and developed preliminary proposals that they presented to the clients and a guest faculty member. The feedback from this presentation included clarification of the differences in the context types. The SS corner lot on the commercial strip demanded more spatial definition without compromising security. The MAP site joined three streets at the interior of the lots and suggested a place of informal assembly. 


\subsection{Refinement}

Based on the feedback from the preliminary review, the students modified the designs and prepared to make final presentations to each group.

\subsubsection{MAP proposal}

MAP has a track record of urban agriculture at the site and articulated its needs clearly. The masterplan proposal includes a strawbale greenhouse addition to the existing frame structure, the tool shed (hut), a central seating retaining wall, a cob oven, a screen for the compost area, and a scrap iron trellised gateway entrance from each of three streets. Existing planting and orchard areas were proposed to be expanded. The first phase would include the greenhouse, fig. 6 and the transforming tool shed, fig. 3.

MAP accepted the proposal and the student team began immediately planning the final design and construction document tasks for the project.

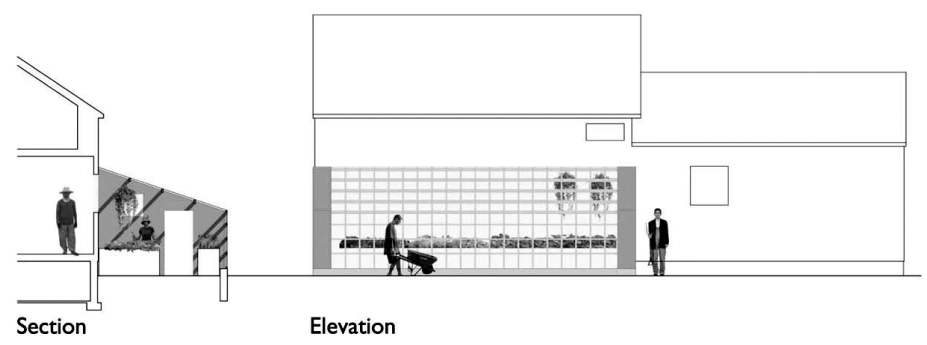

Figure 6: MAP strawbale greenhouse proposal.

\subsubsection{SS proposal}

The existing SS site was reclaimed from dump ground status by the action of volunteers, based on a formal garden design that was prepared without community involvement. The SS team prepared and presented two schemes for the site improvements: one based on the formal garden, fig. 7, but incorporating the adjacent vacant house; the other making a flexible internal green space and confined to the current site boundary. Both schemes create a paved surface area with a gateway entry, fig. 8, as a transition from the commercial street.

The Board approved the project at its public meeting, without choosing a scheme. The first phase would include the rammed earth garden seating wall and cob or earth-bag gateway, as well as a nomadic tool shed.

\section{Build}

Before the spring break, one student developed a more detailed construction activities schedule. The tasks, beginning with a ceremonial ground (and coconut) breaking, carry through the first week of May 2006. This is where the real education about the thinking side of building begins. 


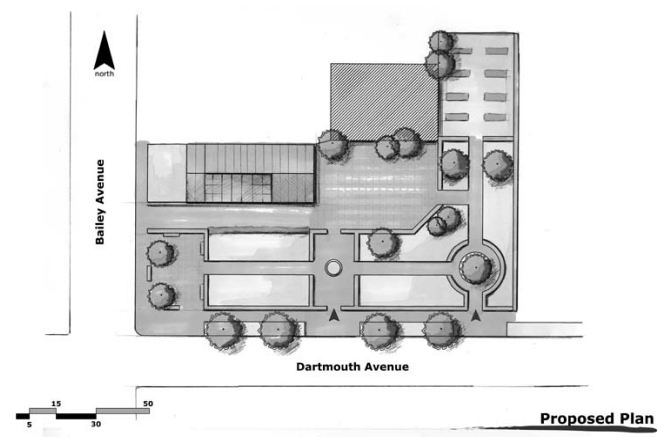

Figure 7: $\quad$ SS garden wall scheme 1.

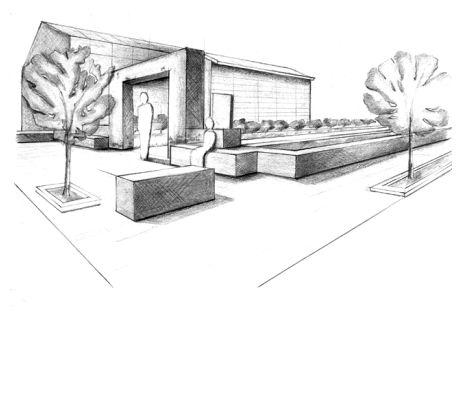

Figure 8: $\quad$ SS entry gateway.

Students will be responsible for developing construction drawings and specifications, quantifying and costing out the materials, assisting in the permitting process, and supporting the client with funding and volunteer participation efforts - in addition to actual construction work. The faculty will direct or negotiate assignments based on past performance.

\section{Discussion}

A Mid-Term Evaluation was conducted to obtain feedback from the students on the trajectory of the seminar. The results were mixed with respect to the content of both testing and real world projects, some expressing the desire to do either one or the other. The hands-on exposure to natural and recycled materials was well received, as was the experience of working with a deserving and appreciative client.

Natural Building Systems has demonstrated the use of natural and recycled materials in architectural education and practice. There remains the need to show the value of building in community, for the growth of architectural students and the community itself. Reflecting on the first half of the semester one student voiced concern about the aesthetics of natural building. Our strawbale mock-up was not the minimalist or computer generated surface of his training. Since much natural building work has been realized in a volunteer context, there is often a 'folk' quality to the finishing, and an organic formal expression. Greater exposure of natural building techniques can expand the range of building and aesthetic possibilities, and increase the range of quality of the work as a whole.

\subsection{Circle of architecture}

Cline [2] is not alone in her willingness to investigate the borderlands of Architecture, "...a region of structures and ideas, a wasteland of heterodoxy defined simultaneously by its proximity to Architecture and its proximity to everything else." It is this everything else which Egenter [5] claims may invigorate architectural theory through inclusivity: "Architectural ethnology 
discovers that traditional societies, e.g. many tribal groups of Southeast Asia, often show very high aesthetic developments... in this respect too, the basic field of architectural phenomena has been enormously enlarged."

From the standpoint of sustainability, the borderlands are fertile regions where alternatives to a consumer building culture abound, including indigenous builders. Rudofsky [6] states, "There is much to learn from architecture before it became an expert's art. The untutored builders in space and time... demonstrate an admirable talent for fitting their buildings into the natural surroundings."

Davis [7] notes that in reality architectural production knows no such borders: "...buildings are built in a world in which most of the various players ... do not fundamentally change the way they work because of Pevsner's distinction between "architecture" and "building." They tend to do the same things, although perhaps to different degrees, on different kinds of buildings."

Natural Building Systems advocates the evolution of architecture out of the process of making as a necessarily communal enterprise. Belonging here to the academy, the mud buildings of 2006 will take their form from any number of influences, from Taos to The Simpsons, from blobs to hyperspace.

\section{References}

[1] Kennedy, J. F., Smith, M. G., \& Wanek, K. (eds.), The Art of Natural Building: Design, Construction, Resources, New Society Publishers: Gabriola Island, p.3, 2002.

[2] Cline, A., A Hut of One's Own: Life Outside the Circle of Architecture, The MIT Press, Cambridge, 1977.

[3] MAP, www.mass-ave.org.

[4] Street Synergy Community Association, Inc., www.streetsynergy.org.

[5] Egenter, N., The Present Relevance of the Primitive in Architecture, Structura Mundi, Lousaine, p.75, 1992.

[6] Rudofsky, B., Architecture Without Architects, University of New Mexico Press, Albuquerque, p.3, 1964.

[7] Davis, H., The Culture of Building, Oxford University Press, New York, p. 10, 1999. 